\title{
SOCIAL SKILL TRAINING PADA PENYANDANG SKIZOFRENIA
}

\author{
Anita E. Dundu \\ Bagian Kedokteran Jiwa Fakultas Kedokteran Universitas Sam Ratulangi Manado \\ Email: anitadundu@yahoo.com
}

\begin{abstract}
Besides psychotic symptoms, schizophrenic patients also show alterations in cognitive function, verbal information, and emotional response, due to disturbances of interpersonal interaction. The impact of all of these is the disturbance in social function. Treatment of schizophrenic patients with psychopharmacotherapy can only suppress the symptoms, but it can not overcome the functional deficit. For this reason, combination of psychopharmacotherapy, psychotherapy, and social rehabilitationin is introduced to obtain a better result in schizophrenic management. Social skill training is a part of the social rehabilitation that is very useful in improving the patients' quality of life in preparing them to be functional in their society.
\end{abstract}

Keywords: schizophrenia, social rehabilitation, social skill training

\begin{abstract}
Abstrak: Pada penyandang skizofrenia selain gejala-gejala psikotik juga terdapat perubahan dalam fungsi kognisi, informasi verbal dan respon emosi akibat terganggunya interaksi interpersonal, yang berdampak gangguan dalam fungsi sosial. Pengobatan skizofrenia dengan menggunakan psikofarmaka hanya dapat menekan gejala-gejala penyakit ini tetapi tidak dapat mengatasi defisit fungsional. Untuk hal ini, pada pengobatan skizofrenia terkini digunakan kombinasi psikofarmaka, psikoterapi dan rehabilitasi sosial. Social skill training merupakan salah satu bagian dari rehabilitasi sosial yang bermanfaat meningkatkan kwalitas hidup dalam mempersiapkan penyandang skizofrenia untuk dapat berfungsi kembali dalam masyarakat.
\end{abstract}

Kata kunci: skizofrenia, rehabilitasi sosial, social skill training

Skizofrenia merupakan gangguan psikotik klasik yang cukup sering ditemukan, yaitu sekitar $1 \%$ dari populasi. Gangguan ini dapat mengenai semua tingkatan sosial, biasanya dimulai sebelum usia 25 tahun, dan berlangsung sepanjang hidup. Penyandang dan keluarga sering terjun dalam ketidakpedulian, dan terisolasi secara sosial karena ketidaktahuan terhadap gangguan ini telah menular luas di dalam masyarakat. ${ }^{1}$

Gangguan neurobiologis pada skizofrenia dapat berupa gangguan persepsi serta gangguan bentuk dan isi pikir yang berdampak pada kognitif, emosi dan perilaku (perubahan dalam hal komunikasi, motivasi, dan perawatan diri). Selain itu juga terdapat gangguan proses informasi dan kognitif dengan adanya halusinasi dan waham; masalah ekspresi; masalah dalam membina serta memelihara hubungan; perubahan emosi; dan masalah sosial pada penyandang skizofrenia sendiri serta keluarganya akibat adanya stigma dalam masyarakat sekitarnya. ${ }^{2-5}$

Manajemen pengobatan pada penyandang skizofrenia meliputi farmakoterapi dan terapi psikososial. Penggunaan antipsikotik merupakan yang terutama untuk menghilangkan gejala, akan tetapi tidak dapat memulihkan kembali fungsi sosialnya. Terapi psikososial dan pelayanan rehabilitasi bertujuan untuk meningkatkan kemampuan sosial melalui praktek ketrampilan, sufisiensi diri, dan ketrampilan dalam berkomunikasi, sehingga dapat menjadi dukungan dalam 
mengatasi ketakutan akan terisolasi akibat stigma yang sering muncul. ${ }^{1,3,5}$

Kombinasi terapi dengan menggunakan antipsikotik dan perencanaan psikoterapi digunakan untuk mencegah kekambuhan dan meningkatkan penyesuaian diri terhadap pengobatan itu sendiri. Manfaat tambahan bila dikombinasi dengan faktor sosial dan terapi psikososial sangat penting pada penyandang skizofrenia secara umum., 1,4-6

\section{PELAYANAN REHABILITASI BAGI PENYANDANG SKIZOFRENIA}

Pada skizofrenia terdapat gangguan kemampuan individu untuk berpikir, merasakan dan menerima serta memahami informasi sensorik, yang selanjutnya menyebabkan terjadinya gangguan perilaku. Gejalagejala skizofrenia ini dapat dikendalikan dengan pengobatan. Walaupan demikian gejala-gejala yang kurang jelas seperti kehilangan minat, kehangatan energi, dan humor tidak berespon baik dengan pengobatan. Gejala ini menyebabkan terjadinya hambatan yang cukup berarti bagi penyandang skizofrenia dan keluarganya.

Rehabilitasi penyandang skizofrenia mencoba untuk meningkatkan fungsi individu. Tujuannya adalah untuk membangun kekuatan dan asset, sekaligus mengurangi defisit fungsi sehari-hari. Penyandang skizofrenia memerlukan kekuatan dan kecakapan hidup secara mandiri dalam masyarakat. Untuk mencapai rehabilitasi yang efektif, maka harus dilakukan secara efektif, komprehensif, terus menerus, serta terkoordinasi, yang melibatkan terapis, keluarga, dan penyandang skizofrenia sendiri. ${ }^{1,3,8}$

Terapi psikososial meliputi: social skill training, family-oriented therapy, case management, assertive community treatment (ACT), group therapy, cognitive behavior therapy, indivual therapy, dan vocational therapy. ${ }^{3}$

\section{Social skill training}

\section{Tujuan pelaksanaan dan proses pen- dekatan}

Social skill training merupakan metode penting dalam rehabilitasi skizofrenia, yang bertujuan agar setelah medikasi, penyandang dapat menjalankan fungsi sosial dan pekerjaannya. ${ }^{2,3,5}$

Pelatihan ketrampilan sosial bertujuan untuk meningkatkan kinerja sosial dan mengurangi tekanan dan kesulitan dalam fungsi sosial. Intervensi psikososial yang dilakukan pada penyandang skizofrenia meliputi penilaian terhadap perilaku, baik yang interpersonal ataupun yang bersifat sosial serta pembelajaran ketrampilan dan komunikasi, baik yang verbal maupun non verbal. $^{2,6,9}$

Social skill training memberikan dukungan dan pelatihan ketrampilan, dukungan emosional, dorongan untuk bekerja, beradaptasi dengan pekerjaannya antara lain berbelanja, mengatur rumah tangga, mengatur waktu dan memanfaatkan waktu luang, bermotivasi dan mempersiapkan diri penyandang skizofrenia untuk kembali ke masyarakat. Hal ini harus dilakukan secara terstruktur yang bertujuan meningkatkan insight terstruktur bagi yang mengalami defisit fungsi interpersonal dengan insight yang kurang terhadap situasi sosial. 3,6,7,10-12

\section{Pelaksanaan social skill training}

Pelaksanaan social skill training melibatkan banyak factor: terapis termasuk dokter, keluarga, social workers, dan penyandang skizofrenia itu sendiri. Sosial skill training dipertahankan sampai penyandang skizofrenia mengalami perbaikan yang menyeluruh. Menurut beberapa studi yang telah dilakukan, social skill training dipertahankan sampai manfaat latihan yang dilakukan sudah dapat diamati; hal ini diperoleh pada saat latihan ketrampilan dan dikonfirmasikan selama terapi. Yang menjadi pertanyaan adalah berapa lama waktu untuk perbaikan yang menyeluruh pada situasi sosial masyarakat tertentu. Hal ini sangat penting pada pengamatan jalannya perbaikan/kemajuan program social skill secara umum dan dalam jangka waktu yang lama, serta keuntungan yang diperoleh dalam lingkungan masyarakat tersebut. ${ }^{3,5,7}$ 
Tabel 1. Tujuan dan perilaku sasaran untuk ketrampilan sosial. ${ }^{3,7,11}$

\begin{tabular}{|c|c|c|}
\hline Fase & Tujuan & Perilaku sasaran \\
\hline $\begin{array}{l}\text { Stabilisasi } \\
\text { dan } \\
\text { penilaian }\end{array}$ & $\begin{array}{l}\text { Menegakkan ikatan terapeutik } \\
\text { Menilai kinerja sosial dan ketrampilan } \\
\text { persepsi } \\
\text { Menilai perilaku yang memprovokasi } \\
\text { emosi yang diekspresikan }\end{array}$ & $\begin{array}{l}\text { Empati dan rapport } \\
\text { Komunikasi verbal dan non } \\
\text { verbal }\end{array}$ \\
\hline $\begin{array}{l}\text { Kinerja } \\
\text { sosial } \\
\text { dalam } \\
\text { keluarga }\end{array}$ & $\begin{array}{l}\text { Mengekspresikan perasaan positif dalam } \\
\text { keluarga } \\
\text { Mengajarkan strategi efektif untuk } \\
\text { menghadapi konflik }\end{array}$ & $\begin{array}{l}\text { Kepatuhan, penghargaan, minat } \\
\text { pada yang lain } \\
\text { Respon menghindar terhadap } \\
\text { kritik, menyatakan kesukaan } \\
\text { dan penolakan }\end{array}$ \\
\hline $\begin{array}{l}\text { Persepsi } \\
\text { sosial } \\
\text { dalam } \\
\text { keluarga }\end{array}$ & $\begin{array}{l}\text { Mengidentifikasi isi, konteks, dan arti } \\
\text { pesan secara benar }\end{array}$ & $\begin{array}{l}\text { Membaca pesan } \\
\text { Melabel suatu gagasan } \\
\text { Meringkaskan maksud orang } \\
\text { lain }\end{array}$ \\
\hline $\begin{array}{l}\text { Hubungan } \\
\text { dalam ke- } \\
\text { luarga }\end{array}$ & $\begin{array}{l}\text { Meningkatkan ketrampilan social } \\
\text { Meningkatkan ketrampilan prakejuruan } \\
\text { dan kejuruan }\end{array}$ & $\begin{array}{l}\text { Ketrampilan bercakap-cakap } \\
\text { Bersahabat } \\
\text { Aktivitas reaksional } \\
\text { Wawancara kerja, kebiasan } \\
\text { kerja }\end{array}$ \\
\hline $\begin{array}{l}\text { Pemeliha- } \\
\text { raan }\end{array}$ & $\begin{array}{l}\text { Generalisasi ketrampilan ke dalam situasi } \\
\text { baru }\end{array}$ & \\
\hline
\end{tabular}

\section{Pelaksanaan social skill training}

Pelaksanaan social skill training melibatkan banyak factor: terapis termasuk dokter, keluarga, social workers, dan penyandang skizofrenia itu sendiri. Sosial skill training dipertahankan sampai penyandang skizofrenia mengalami perbaikan yang menyeluruh. Menurut beberapa studi yang telah dilakukan, social skill training dipertahankan sampai manfaat latihan yang dilakukan sudah dapat diamati; hal ini diperoleh pada saat latihan ketrampilan dan dikonfirmasikan selama terapi. Yang menjadi pertanyaan adalah berapa lama waktu untuk perbaikan yang menyeluruh pada situasi sosial masyarakat tertentu. Hal ini sangat penting pada pengamatan jalannya perbaikan/kemajuan program social skill secara umum dan dalam jangka waktu yang lama, serta keuntungan yang diperoleh dalam lingkungan masyarakat tersebut. ${ }^{3,5,7}$ Pelaksanaan social skill training dapat dilakukan antara lain dengan: ${ }^{7,13}$
- Social skill group: Terdiri dari beberapa orang. Meningkatkan kemampuan penyandang untuk membangun hubungan sosial dan memenuhi peran sosial. Dimulai dengan role play, memperagakan dan membuat pekerjaan rumah, meningkatan ketrampilan berbicara, menangani masalah, bersifat tegas, bersahabat dan berkencan, memperlihatkan ketrampilan dalam mengatur medikasi dan dalam hidup bermasyarakat, serta vocational work skill.

- Anger management: Membantu penyandang untuk mengenal dan mengerti pengaruh dari tingkah laku bila marah. Juga menolong penyandang meningkatkan ketrampilan dalam menghadapi kemarahan melalui latihan, role play dan grup diskusi.

- Women's empowerment: Ditujukan untuk kasus yang berhubungan dengan gangguan emosi dan pelecehan seksual, tingkah laku yang dapat merusak dirinya, emosi yang memburuk dan perasa- 
an rendah diri, agar penyandang dapat bersifat tegas dan memelihara teknik meningkatkan kekuatan dirinya.

- Kepercayaan diri: Memberikan ketrampilan dan teknik pada penyandang dalam meningkatkan harga diri.

- Latihan hidup bermasyarakat: Membantu penyandang untuk berintegrasi dalam masyarakat dengan belajar menggunakan pelayanan dan fasilitas masyarakat. Sebagai tambahan, juga membantu penyandang dalam hal ketrampilan mengenali kebutuhan hidup.

- Kelompok pria: Difokuskan pada berbagi pengalaman dengan pria sebaya. Juga berbicara dan beraktifitas dalam diskusi dengan teman, serta mengadakan acara-acara unik yang bersifat maskulin bersama-sama.

- Kelompok wanita: Membantu dan memberi edukasi penyandang dalam mengenali persoalan wanita yang dapat mempengaruhi baik fisik maupun emosi.

- Masalah keluarga: Kesehatan keluarga dapat menyebabkan disfungsi penyandang pada suatu saat tertentu. Pelatihan dalam kelompok ini mendorong penyandang untuk menceritakan tentang kesulitan dalm hubungan keluarga, serta perasaan-perasaan yang positif dan negatif yang terdapat di dalam keluarga.

\section{Contoh bentuk pelaksanaan social skill training}

Salah satu bentuk pelaksanaan social skill training yang dilakukan oleh Rosberg di klinik Anne Sippi Clinic (1998) adalah mengajari suatu kelompok tentang bagaimana mengatur waktu, menentukan sasaran, dan berkonsentrasi untuk periode waktu yang semakin bertambah terhadap suatu perintah. Hal ini bertujuan untuk meningkatkan ketrampilan kerja dan edukasi yang nantinya diharapkan akan dapat berhasil diterapkan dalam masyarakat umum. Aktivitas ini diawasi oleh direktur rehabilitasi dan asisten dari case manager. Beberapa hal yang dilakukan disini adalah: ${ }^{2-7,12}$

1. Berkebun (gardening/landscaping): Residen bekerja dengan terapis dan case manager dalam membuat kebun sayur dan kebun mawar di belakang klinik untuk keperluan dapur dan keindahan klinik. Penyandang diajarkan bagaimana menggunakan pakaian yang sesuai untuk bekerja dengan tanah dan bahan tanaman, serta bagaimana cara menggunakan alat perkebunan dan membersihkan alat tersebut bila telah selesai dipakai. Juga diajari jenis-jenis tanaman yang sesuai dengan musim; cara mempersiapkan tanah; menyiangi; menyirami tanaman dan hasil panen; pengetahuan mengenai tanaman, pupuk, dan serangga; cara menanam secara teratur; pembelian dan pembelanjaan yang dibutuhkan; serta transportasi yang diperlukan pada kebun.

2. Mengecat: Residen bekerja dengan maintenance staff. Penyandang diajarkan bagaimana mencampur cat, menggunakan kuas, mempersiapkan ruangan yang akan di cat, membersihkan cat dan kuas, serta memperbaiki kembali ruangan seperti sebelum dicat.

3. Pemeliharaan ruangan: Residen berkerja dengan case manager mengkoordinasi dan membersihkan ruangan residen dan barang-barang pribadi. Penyandang diajarkan bagaimana menata dan mengatur ruangan suapaya tampak indah serta ruangan dapat dipergunakan semaksimal mungkin. Diajarkan pula bagaimana menggunakan sapu dan dustpan, alat mengepel dan alat pembersih lainnya, serta memilih pakaian yang sesuai dan cara membersihkannya setelah selesai.

4. Ketrampilan berbelanja: Residen bekerja dengan supervisor bagian makanan, mempelajari cara menghitung dan membagi dana, mengerti nilai dan barang yang akan dibeli, mampu menyeleksi barang yang penting dan diperlukan untuk makanan dan kehidupan seharihari, serta mengatur waktu pembelian serta mencari transportasi.

Perlu dicamkan bahwa dalam pelaksanaan social skill training, peran anggota staf yang telah terlatih sangat dibutuhkan untuk mendapatkan hasil yang optimal. 


\section{SIMPULAN}

Dalam penatalaksaan skizofrenia dibutuhkan psikofarmaka untuk mengobati gejala-gejala yang ada, terapi psikososial dan rehabilitasi, disamping memberikan dukungan pada penyandang dalam mengatasi penyakit, ketakutan, terisolasi, serta stigma yang sering muncul. Juga membantu penyandang dalam meningkatkan keterampilan dan kualitas hidup. Terapi psikososial dan rehabilitasi dapat dikategorikan sebagai target pengganti utama pada defisit fungsional melalui latihan-latihan intervensi, antara lain melalui social skill training.

Social skill training menggunakan teknik modifikasi tingkah laku dengan multimedia training program, menyajikan role playing exercise, dan mendemostrasikan lewat videotape interaksi antara penyandang, dokter dan terapis, serta membuat pekerjaan rumah.

Dengan memberikan dukungan dan tuntunan dalam ketrampilan, dukungan emosional, dorongan untuk beradaptasi pada kehidupan sehari-hari dan berkesadaran sosial, diharapakan dapat memperbaiki kualitas hidup penyandang skizofrenia sekaligus mempersiapkannya utnuk dapat berfungsi dalam masyarakat.

\section{DAFTAR PUSTAKA}

1. Sadock BJ, Sadock VA. Kaplan \& Sadock's Synopsis of Psychiatry. Behavioral Sciences/Clinical Psychiatry (Tenth Edition). Philadelphia: Wolters Kluwer Health/Lippincott William and Wilkins, 2000.

2. Kopelowicz A, Liberman RP, Wallace CJ. Psychiatric rehabilitation for schizophrenia. Intern Jour Psych Psychol Ther. 2003;3(2):283-98.

3. Kaplan HI, Sadock BJ. Kaplan and Sadock's Comprehensive Textbook of Psychiatry (Seventh Edition). Philadelphia: Lippincot Williams \& Wilkins, 2000.

4. Kuipers E, Garety P, Fowler D, Freeman D, Dunn G, Bebbington P. Cognitive, emotional, and social processes in psychosis: Refining cognitive behavioral therapy for persistent positive symptoms. Schizophr Bull. 2006;32(S1):S24-31.

5. Velligan DI, Bow-Thomas CC. Two case studies of cognitive adaptation training for outpatients with schizophrenia. Rehab Rounds. Psychiatr Serv 2000;51 (1):25-29. [cited 2010 Oct 15] Available from: http://psychservices.psychiatryonline.org/cgi/reprint/51/1/25.pdf.

6. Heinssen RK, Liberman RP, Kopelowicz A. Psychosocial skills training for schizophrenia: Lessons from the laboratory. Schizoph Bull. 2010;26(1):21-46.

7. Bellack, Mueser KT, Gingerich S, Agresta J. Social Skill Training For Schizophrenia $2^{\text {nd }}$ Edition: A Step by Step Guide. New York: Guilford Press,2004.

8. Spaniol L. Recorvery from Psychiatric Disability: Implication for rehabilitation Counseling Education. National Council on Rehabilitation Education. Rehabilitation educational 2001;15(2):167-75. [cited 2010 Oct 15]. Available from: http://www.bu.edu/cpr/resources/article/ 2001/spaniol2001/pdf.

9. Bhurga D. Schizophrenia. The Nice Guideline on core interventions in the treatment and management of schizophrenia in adults in primary and secondary care. Updated edition. National Clinical Guideline Number 82. National collaborating centre for mental health and clinical excellence. London: The British Psychological Society and the Royal College of Psychiatrists, 2010.

10. Caton CLM, Hasin DS, Shrout PE, Drake RE, Dominguez B, First MB et al. Stability of early-phase primary psychotic disorders with concurrent substance use and substance-induced psychosis. $\mathrm{Br}$ J Psychiatry 2007;190:105-11.

11. Thornicroft G, Bebbington P. Deinstitutionalisation-from hospital closure to service development. Br J Psychiatry 1989;155:739-53.

12. Lloyd C, Tse S, Deane FP. Community participation and social inclusion: How practitioners can make a difference. AeJAMH 2006;5(3):1-10.

13. Thomson LDG. Management of schizophrenia in conditions of high security. Advances in Psychiatric treatment. Journal of continuing professional development. Adv. Psychiatr. Treat. 2000;6: 252-60. 